Title:

\title{
Isolation and Catalytic Reactivity of Mononuclear Palladium(I) Complexes
}

Authors: Giang N. Tran, ${ }^{1}$ Bailey S. Bouley, ${ }^{1}$ and Liviu M. Mirica ${ }^{1, *}$

Affiliations:

${ }^{1}$ Department of Chemistry, University of Illinois at Urbana-Champaign; Urbana, Illinois, 61801. *Corresponding author: mirica@illinois.edu

\begin{abstract}
:
Palladium complexes are among the most commonly used transition metal catalysts for different organic transformations with wide applications in the chemical synthesis. Currently, catalytic transformations involving $\mathrm{Pd}(0) / \mathrm{Pd}(\mathrm{II})$ catalytic cycles are very well-known, and processes involving $\mathrm{Pd}(\mathrm{II}) / \mathrm{Pd}(\mathrm{III}) / \mathrm{Pd}(\mathrm{IV})$ intermediates are also gaining interest in recent years due to the increasing relevance of high-valent Pd species. By contrast, isolated low-valent $\mathrm{Pd}(\mathrm{I})$ complexes, especially mononuclear $\operatorname{Pd}(\mathrm{I})$ species, are very rare. Herein, we report the isolation of two heteroleptic $\operatorname{Pd}(\mathrm{I})$ complexes stabilized by dithiapyridinophane ligands that were fully characterized by single-crystal X-ray diffraction, EPR, IR, and UV-Vis spectroscopies, and computational studies. Excitingly, these $\mathrm{Pd}(\mathrm{I})$ complexes are shown to be superior catalysts for the Csp $p^{2}$-Csp $p^{3}$ Kumada cross-coupling reaction vs. their $\mathrm{Pd}(0)$ or $\mathrm{Pd}(\mathrm{II})$ analogs.
\end{abstract}

\section{One-Sentence Summary:}

Two uncommon heteroleptic Palladium(I) complexes were isolated and characterized, and their reactivity in cross-coupling reactions was investigated. 


\section{Main Text:}

Palladium-catalyzed organic transformations have gained tremendous interest over the past few decades, especially in the contex of cross-coupling reactions. ${ }^{1-4}$ In these systems, while the general reaction mechanism involves a $\mathrm{Pd}^{0} / \mathrm{Pd}^{\mathrm{II}}$ catalytic cycle, ${ }^{1,5}$ several reports proposed the involvement of $\mathrm{Pd}^{\mathrm{I}}$ intermediates. ${ }^{6-22}$ Additionally, while there are many examples of transient $\mathrm{Pd}^{\mathrm{I}}$ species $^{23-30}$ as well as isolated $\mathrm{Pd}^{\mathrm{I}}$ dimers, ${ }^{31-34}$ there are very few examples of well-established monomeric Pd complexes bearing a formal +1 oxidation state at $\mathrm{Pd}$. To the best of our knowledge, only two structurally characterized examples of isolated $\mathrm{Pd}^{\mathrm{I}}$ complexes - the cationic $\left[\mathrm{Pd}^{\mathrm{I}}\left(\mathrm{P}^{\mathrm{t}} \mathrm{Bu}_{3}\right)_{2}\right]^{+}$ species and the $\left[\mathrm{Pd}^{\mathrm{I}}(\mathrm{MeCN})\left(\mathrm{P}^{t} \mathrm{Bu}_{3}\right)_{2}\right]^{+}$complex, have been reported independently by Chaplin's and Ozerov's groups, respectively. ${ }^{35,36} \mathrm{With}$ the goal of isolating and characterizing mononuclear $\mathrm{Pd}^{\mathrm{I}}$ species and explore their reactivity, we report herein the synthesis and characterization of two unique heteroleptic $\operatorname{Pd}(\mathrm{I})$ complexes supported by dithiapyridinophane macrocyclis ligands and their catalytic reactivity in Kumada cross-coupling reactions.

A

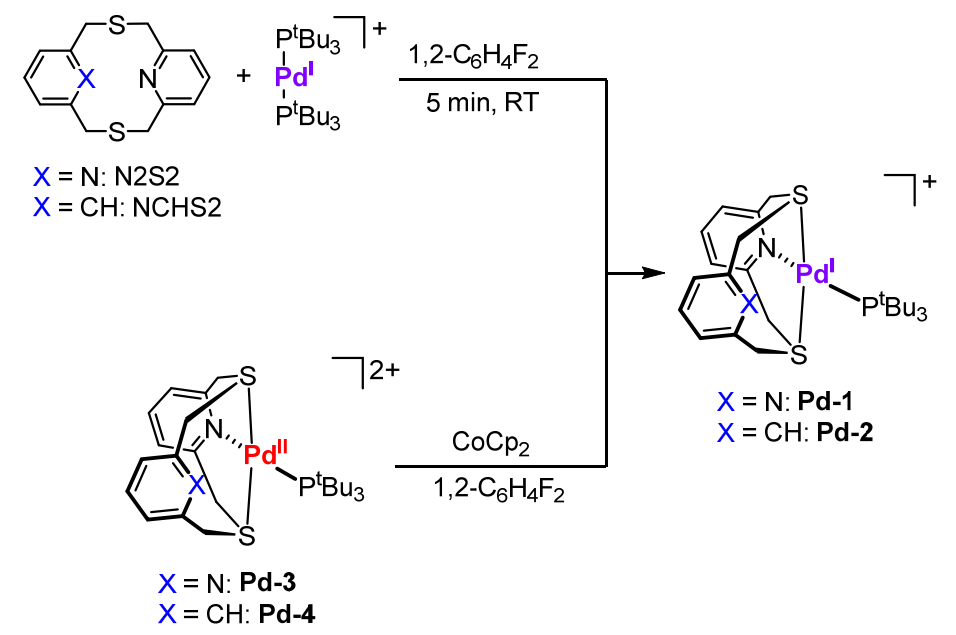

B

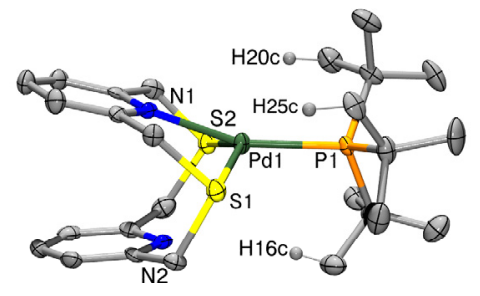

C

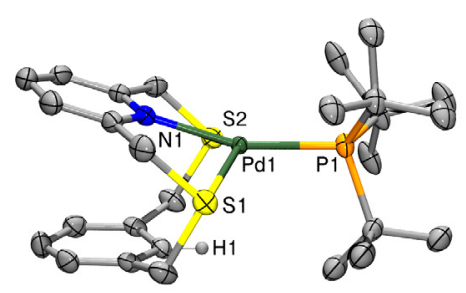

Fig. 1. Synthetic routes for Pd-1 and Pd-2 and their X-ray crystal structures. (A) Two different pathways for the synthesis of Pd-1 and Pd-2. (B) and (C) ORTEP representations (50\% probability ellipsoids) of the cations of Pd-1 (B) and Pd-2 (C). Selected bond distances $(\AA)$ and angles $\left(^{\circ}\right)$ for Pd-1: Pd1-N1 2.212(5), Pd1-P1 2.3401(16), Pd1-S1 2.4475(16), Pd1-S2

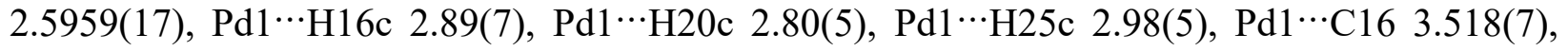
Pd1C20 3.474(7), Pd1C25 3.657(7), Pd1-H16c-C16 130.0(6), Pd1-H20c-C20 124.0(4), Pd1-H25c-C25 128.0(4); and Pd-2: Pd1-N1 2.200(3), Pd1-P1 2.3561(13), Pd1-S1 2.5245(16),

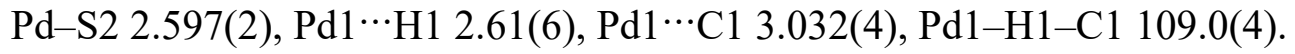


We have previously reported the detection of a series of transient mononuclear $\mathrm{Pd}^{\mathrm{I}}$ complexes supported by the tetradentate ligand 2,11-dithia[3.3](2,6)pyridinophane (N2S2). ${ }^{30}$ These $\mathrm{Pd}^{\mathrm{I}}$ monomers were synthesized through one-electron reduction of their $\mathrm{Pd}^{\mathrm{II}}$ analogs. The sulfur atoms from $\mathrm{N} 2 \mathrm{~S} 2$ are proposed to be soft donor atoms, which help to stabilize the reactive $\mathrm{Pd}^{\mathrm{I}}$ metal center. Even though we were able to confirm the formation of the paramagnetic, low-valent species through electron paramagnetic resonance (EPR) spectroscopy, no crystal structures were obtained due to the instability of the complexes even at low temperature. Inspired by the observation of these transient mononuclear $\mathrm{Pd}^{\mathrm{I}}$ species, we continued to employ $\mathrm{N} 2 \mathrm{~S} 2$ as well as another 10 dithiapyridinophane ligand, 3,7-dithia-1(2,6)-pyridina-5(1,3)-benzenacyclooctaphane (NCHS2). In terms of the ancillary ligands, phosphines captured our interest not only due to their soft donor nature, but also due to the recent independent reports by Chaplin et al. and Ozerov et al. in isolating the $\left[\mathrm{Pd}^{\mathrm{I}}\left(\mathrm{P}^{\mathrm{t}} \mathrm{Bu}_{3}\right)_{2}\right]^{+}$complexes. ${ }^{35,36} \mathrm{We}$ first sought out to synthesize this $\mathrm{Pd}^{\mathrm{I}}$ precursor and further characterize it through EPR by using a glassing solvent mixture (either 1:1 1,2-difluorobenzene:2MeTHF or 1:3 MeCN:PrCN), which gave well-defined superhyperfine coupling to the two ${ }^{31} \mathrm{P}$ atoms in the $\mathrm{g}_{z}$ direction couplings even at $77 \mathrm{~K}$, both for the $\left[\mathrm{Pd}^{\mathrm{I}}\left(\mathrm{P}^{t} \mathrm{Bu}_{3}\right)_{2}\right]^{+}$and the $\left[\mathrm{Pd}^{\mathrm{I}}\left(\mathrm{PBu}_{3}\right)_{2}{ }^{(\mathrm{MeCN})}\right]^{+}$complexes (figs. S5 and $\left.\mathrm{S} 6\right)^{35,36}$ To our delight, the complexes $\left[(\mathrm{N} 2 \mathrm{~S} 2) \mathrm{Pd}^{\mathrm{I}}\left(\mathrm{P}^{\mathrm{t} B u} 3\right)\right]^{+}(\mathbf{P d}-1)$ and $\left[(\mathrm{NCHS} 2) \mathrm{Pd}^{\mathrm{I}}\left(\mathrm{P}^{\mathrm{t}} \mathrm{Bu}_{3}\right)\right]^{+}(\mathbf{P d}-2)$ were obtained upon the reaction of $\left[\mathrm{Pd}^{\mathrm{I}}\left({ }^{\mathrm{B}} \mathrm{Bu} 3 \mathrm{P}\right)_{2}\right]^{+}$with N2S2 or NCHS2 in 1,2-difluorobenzene (DFB, Fig. 1A). Pd-1 and Pd-2 were 20 crystallized by slow diffusion of n-pentane into DFB at $-35^{\circ} \mathrm{C}$, and their single crystal X-ray structures reveal that the Pd-P bond of Pd-1 and Pd-2 are 2.3401(16) $\AA$ and 2.3561(13) $\AA$, respectively (Figs. 1B and 1C), which are comparable to the average Pd-P bond length of 2.3469(6) $\AA$ for $\left[\mathrm{Pd}^{\mathrm{I}}\left(\mathrm{P}^{\mathrm{t}} \mathrm{Bu}_{3}\right)_{2}\right]^{+} .35,36$ Each Pd center is four-coordinate, with the N2S2 or NCHS2 ligand binding in a $\kappa^{3}$ conformation, while the $\mathrm{P}^{\mathrm{t}} \mathrm{Bu} 3$ ligand completes the coordination environment. Interestingly, each $\mathrm{tBu}$ group of the $\mathrm{P}^{\mathrm{t}} \mathrm{Bu}$ ligand has one methyl $\mathrm{C}-\mathrm{H}$ bond oriented toward the $\mathrm{Pd}$ center, the shortest P...H-C distance being $2.80 \AA$ (Figure 1B), and this likely plays a role in the stability of Pd-1 and its mode of decomposition. By comparison, in Pd-2 the shortest Pd...H distance of $2.61 \AA$ is observed for the $\mathrm{C}_{\mathrm{ips}}-\mathrm{H}$ group of the phenyl ring in the NCHS2 ligand, although the rigid nature of the macrocyclic ligand likely hinders further interaction with the $\mathrm{Pd}$ center. Both complexes exhibit a distorted seesaw geometry, with the geometry index of $\tau^{\prime} 4=$ 0.161 for Pd-1 and $\tau^{\prime}{ }_{4}=0.166$ for Pd-2, respectively. ${ }^{37}$ In our previous study, we were able to 
fully characterize the $\mathrm{Pd}^{\mathrm{I}}$ dinuclear complex $\left[(\mathrm{N} 2 \mathrm{~S} 2) \mathrm{Pd}^{\mathrm{I}}(\mu-\mathrm{BuNC})\right]_{2}\left(\mathrm{ClO}_{4}\right)_{2}{ }^{30}$ While in this $\mathrm{Pd}^{\mathrm{I}}$ dinuclear complex the N2S2 ligand interacts with the Pd center through only one $\mathrm{Pd}-\mathrm{S}$ bond, the NXS2 ligands $(\mathrm{X}=\mathrm{N}$ or $\mathrm{CH})$ in the mononuclear complexes Pd-1 and Pd-2 have both $\mathrm{S}$ atoms bind to the Pd center. Interestingly, given the presence of the two S soft donors, we were able to observe what is to the best of our knowledge the first four-coordinate, mononuclear $\mathrm{Pd}^{\mathrm{I}}$ complexes with an unambiguous +1 oxidation state at the Pd center.

In addition, we have synthesized the $\mathrm{Pd}^{\mathrm{II}}$ complexes $\left[(\mathrm{N} 2 \mathrm{~S} 2) \mathrm{Pd}^{\mathrm{II}}\left(\mathrm{P}^{\mathrm{t}} \mathrm{Bu} 3\right)_{2}\right]^{2+}, \mathbf{P d}-\mathbf{3}$, and $\left[(\mathrm{N} 2 \mathrm{~S} 2) \mathrm{Pd}^{\mathrm{II}}\left(\mathrm{P}^{\mathrm{t}} \mathrm{Bu}_{3}\right)_{2}\right]^{2+}$, Pd-4 (Fig. 1A), which exhibit well-defined, reversible $\mathrm{Pd}^{\mathrm{II}} / \mathrm{Pd}^{\mathrm{I}}$ redox waves at $-0.47 \mathrm{~V}$ for $\mathbf{P d - 3}$ and $-0.38 \mathrm{~V}$ vs. $\mathrm{Fc}^{0 /+}$ for $\mathbf{P d - 4}$, respectively (figs. S3 and S4). Interestingly, the $\mathrm{Pd}^{\mathrm{I}}$ complexes Pd-1 and Pd-2 could also be synthesized via the one-electron reduction by $\mathrm{CoCp}_{2}$ of Pd-3 and Pd-4 using (Fig. 1A), as confirmed by the EPR spectra of the reduced complexes that are identical to the isolated Pd-1 and Pd-2 complexes (see below).

Both Pd-1 and Pd-2 were characterized by UV-Vis spectroscopy, Evan's method, EPR spectroscopy, and theoretical calculations. The stability of these $\mathrm{Pd}^{\mathrm{I}}$ complexes was investigated by UV/Vis spectroscopy by monitoring the formation and decay of Pd-1 and $\mathbf{P d - 2}$ for a longer times at RT. There was no indication of degradation of the intensities of the UV-vis absorption bands for up to $\sim 80$ minutes for both Pd-1 ( $\lambda_{\max }=334 \mathrm{~nm}$, fig. S15) and Pd-2 ( $\lambda_{\max }=342 \mathrm{~nm}$, fig. S17). At longer times, a slow decay was observed for both complexes (figs. S16 and S18), UV-vis absorption bands decreasing by $<10 \%$ and $<5 \%$ after $4 \mathrm{~h}$ at RT for Pd-1 and Pd-2, respectively. Overall, the UV-Vis data indicate a slower decay for Pd-2 compared to Pd-1, whether at RT or low temperature, which is likely playing a role in their reactivity profiles (see below).

Complexes Pd-1 and Pd-2 are paramagnetic and exhibit effective magnetic moments $\mu_{\text {eff }}$ of 1.69 and $1.72 \mu_{\mathrm{b}}$ at RT, respectively, corresponding to one unpaired electron. The EPR spectrum of Pd-1 in a 1:1 1,2- $\mathrm{C}_{6} \mathrm{H}_{4} \mathrm{~F}_{2}: 2-\mathrm{MeTHF}$ solvent mixture glass at $77 \mathrm{~K}$ reveals an axial signal with $g_{x}=g_{y}=2.050$ and $g_{z}=2.219$, along with superhyperfine coupling interactions with the ${ }^{31} \mathrm{P}$ atom ( $I=1 / 2,100 \%$ abundance) of $96 \mathrm{G}$ and $79 \mathrm{G}$ in the $\mathrm{x} / \mathrm{y}$ and $\mathrm{z}$ directions, respectively (Fig. 2A). In contrast, the EPR spectrum of Pd-2 shows a rhombic signal $g_{x}=2.030, g_{y}=2.070$, and $g_{z}=2.237$, along with superhyperfine coupling constants of $96 \mathrm{G}, 76 \mathrm{G}$, and $69.5 \mathrm{G}$ in the $\mathrm{x}, \mathrm{y}$, and $\mathrm{z}$ directions, respectively (Fig. 2B). The more anisotropic nature of the EPR spectrum of Pd-2 than that of Pd-1 is likely due to the presence of a phenyl group instead of a pyridyl group in the NCHS2 ligand, which decreases the symmetry about the $\mathrm{Pd}^{\mathrm{I}}$ center in $\mathbf{P d - 2}$. For Pd-1, is it possible that in 
solution a dynamic exchange between the two pyridine $\mathrm{N}$ donors that can bind to the Pd center can generate a pseudo-trigonal bipyramidal 5-coordinate $\mathrm{Pd}^{\mathrm{I}}$ center, and thus lead to a more axial EPR spectrum. The EPR experiments also indicate that these two $\mathrm{Pd}^{\mathrm{I}}$ complexes are quite stable at low temperature, an appreciable amount of EPR signal being observed even after storing the two $\mathrm{Pd}^{\mathrm{I}}$ solutions at $-80^{\circ} \mathrm{C}$ for up to 10 days (figs. S9 and S12). Taken together, the observed structural and EPR parameters for Pd-1 and Pd-2 strongly suggest the presence of a $\mathrm{d}^{9} \mathrm{Pd}^{\mathrm{I}}$ center with the unpaired electron being localized mainly in the $d_{x 2}-\mathrm{y} 2$ orbital.
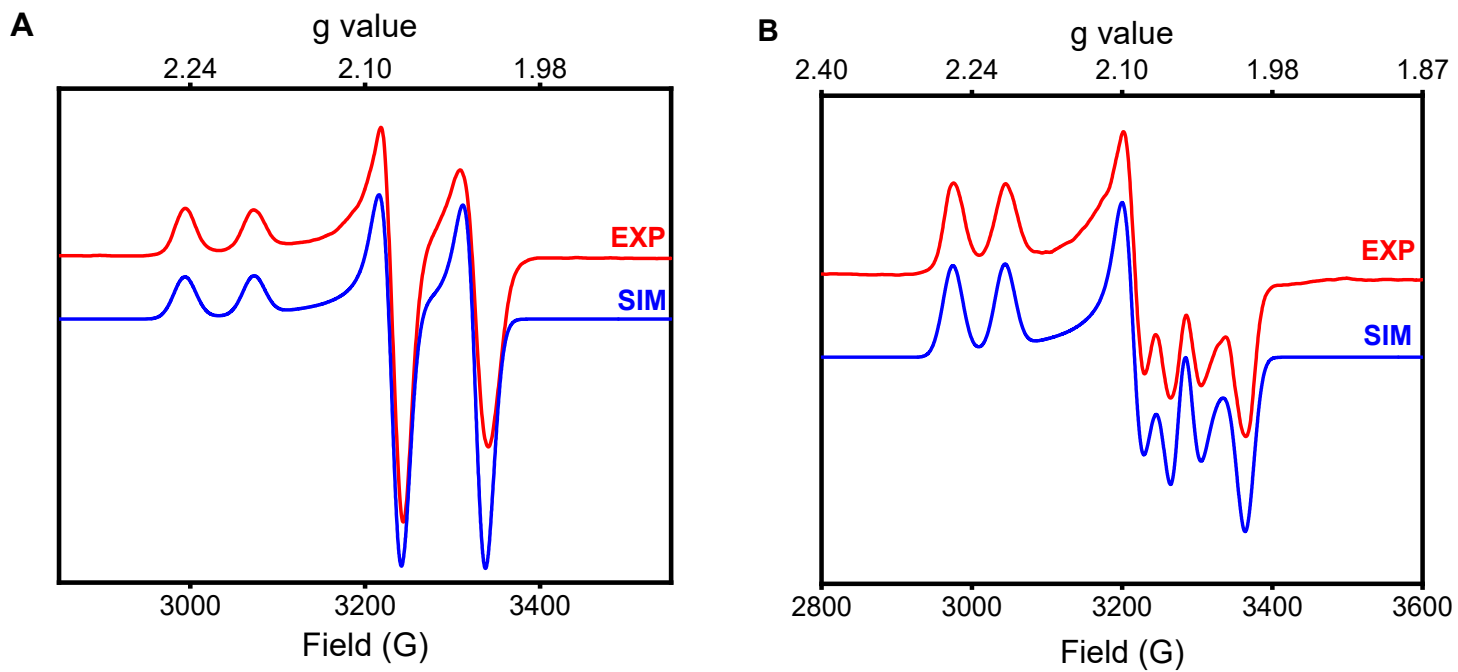

10 Fig. 2. EPR spectra (red lines) of (A) Pd-1 and (B) Pd-2 in 1:1 DFB:2-MeTHF glass at $77 \mathrm{~K}$, and the simulated EPR spectra (blue lines) using the following parameters: (A) $g_{x}=g_{y}=2.050\left(A_{P}=\right.$ $96 \mathrm{G}), g_{z}=2.219\left(A_{P}=79 \mathrm{G}\right) ;(\mathbf{B}) g_{x}=2.030\left(A_{P}=96 \mathrm{G}\right), g_{y}=2.070\left(A_{P}=76 \mathrm{G}\right), g_{z}=2.237\left(A_{P}\right.$ $=69.5 \mathrm{G}$ ).

Density functional theory (DFT) calculations support a metal-based radical description for the $\mathrm{Pd}^{\mathrm{I}}$ complexes Pd-1 and Pd-2. The DFT-calculated spin density for Pd-1 shows the unpaired electron resides mostly $(\sim 65 \%)$ on the Pd center - specifically in the $\mathrm{d}_{\mathrm{x} 2-\mathrm{y} 2}$ orbital, with appreciable contribution from the $\mathrm{P}$ atom $(8.4 \%)$, the two $\mathrm{S}$ atoms (16\% combined), and the equatorial $\mathrm{N}$ atom (4.5\%, Table 1), while for Pd-2 the calculated spin density is localized mostly $(\sim 62 \%)$ on the Pd center, with appreciable contribution from the $\mathrm{P}$ atom $(8 \%)$, the two $\mathrm{S}$ atoms $(15.6 \%$ combined), and the $\mathrm{N}$ atom (4\%, Table 1). Importantly, the appreciable contribution of the $\mathrm{P}$ atom to the spin density supports the observed superhyperfine coupling constants observed in all three $\mathrm{x} / \mathrm{y} / \mathrm{z}$ directions, while the DFT-calculated g values and superhyperfine coupling constants for Pd-1 and 
Pd-2 are closely matching the experimental values (Table 1). Furthermore, the average value ( $\left.\mathrm{A}_{\text {iso }}\right)$ of the ${ }^{31} \mathrm{P}$ superhyperfine coupling constants and extent of anisotropy for the $A_{x}, A_{y}$, and $A_{z}$ values can be used to calculate the contributions of the $\mathrm{P} 3 s$ and $3 p$ orbitals to the spin density, respectively, following the method developed by Morton and Preston. ${ }^{38}$ Using this approach and based on the experimental Ap values, it can be calculated that in Pd-1 the P $3 s$ and $3 p$ orbitals contribute $1.8 \%$ and $4.4 \%$ to the unpaired electron spin density, respectively, for a total of $6.2 \%$ contribution of the $\mathrm{P}$ atom to the spin density. Similarly, it was determined that in $\mathbf{P d}-\mathbf{2}$ the $\mathrm{P} 3 s$ and $3 p$ orbitals contribute $1.7 \%$ and $6.8 \%$ to the unpaired electron spin density, respectively, for a total of $8.5 \%$ contribution of the $\mathrm{P}$ atom to the spin density. Overall, these experimentally-derived $\mathrm{P}$ atom contributions to the spin density are in excelled agreement with the DFT-calculated values, and strongly support the metalloradical nature of these $\mathrm{Pd}^{\mathrm{I}}$ complexes.

Table 1. DFT-Calculated Mulliken spin densities for Pd-1 and Pd-2 (shown as 0.05 isodensity contour plots), along with the relevant atomic orbital contributions to the spin density, and the experimental and calculated EPR parameters.

\begin{tabular}{ccccccc}
\hline Complex & & & & & & \\
\hline
\end{tabular}


We have also investigated the reactivity of these complexes towards Kumada cross-coupling reactions (Table 2). We have observed that both Pd-1 and Pd-2 promote the coupling between the secondary alkyl nucleophile cyclohexylMgCl and iodobenzene. We have also investigated the efficiency of the catalysts by examining the reactivity of $\left[\mathrm{Pd}^{0}\left(\mathrm{P}^{t} \mathrm{Bu}_{3}\right)_{2}\right]^{+},\left[\mathrm{Pd}^{\mathrm{I}}\left(\mathrm{P}^{\mathrm{t}} \mathrm{Bu}_{3}\right)_{2}\right]^{+}$, as well as the $\left[(\mathrm{NXS} 2) \mathrm{Pd}^{\mathrm{II}}\left({ }^{\mathrm{t}} \mathrm{Bu} 3 \mathrm{P}_{2}\right)_{2}\right]^{2+}$ complexes $\mathbf{P d}-\mathbf{3}$ and $\mathbf{P d}-\mathbf{4}$, under similar conditions. While $\left[\mathrm{Pd}^{0}\left(\mathrm{P}^{t} \mathrm{Bu}_{3}\right)_{2}\right]^{+}$yields only $11 \%$ of cross-coupled produt (Table 2, entry 1$),\left[\mathrm{Pd}^{\mathrm{I}}\left(\mathrm{P}^{\mathrm{t}} \mathrm{Bu}_{3}\right)_{2}\right]^{+}$gives a moderate yield of 53\% for the cross-coupled product (Table 2, entry 2). Excitingly, both Pd-1 and Pd-2 give superior yields of the cross-coupled product of $74 \%$ and $96 \%$, respectively, within 20 minutes at low temperature (Table 2, entries 3 and 4), Pd-2 being a particularly efficient catalyst, yielding 96\% product without any $\mathrm{PhI}$ starting material left (fig. S19). The superior reactivity observed for Pd-2 is likely due to its increased thermal stability, as well as the absence of the second coordinating pyridyl group that could block the access of the substrate(s) to the Pd center. Finally, the Pd ${ }^{\mathrm{II}}$ complexes Pd-3 and Pd-4 gave $<10 \%$ yield of the cross-coupled product (Table 2 , entries 5 and 6). Importantly, these findings strongly support that $\mathrm{Pd}^{\mathrm{I}}$ centers can serve as active catalysts for cross-coupling reactions. To the best of our knowledge, this is the first example of a $\mathrm{C} s p^{2}$-Cs $p^{2}$ Kumada cross-coupling reaction catalyzed by isolated mononuclear $\mathrm{Pd}^{\mathrm{I}}$ complexes, and supports the role of $\mathrm{Pd}^{\mathrm{I}}$ species in the Kumada cross-coupling proposed by Knochel et al. upon the generation in situ of $\mathrm{Pd}^{\mathrm{I}}$ intermediates formed in presence alkyl iodides. ${ }^{7}$ We have also compared the catalytic reactivity between these $\mathrm{Pd}^{\mathrm{I}}$ complexes and related $\mathrm{Ni}^{\mathrm{I}}$ systems, as $\mathrm{Ni}$ is known to be found more easily in odd oxidation states. While well-characterized $\mathrm{Ni}^{\mathrm{I}}$ complexes were reported or proposed as precatalysts for several organic transformations,${ }^{39}$ there are few studies on isolated $\mathrm{Ni}^{\mathrm{I}}$ complexes as the catalytically active species for Kumada cross-coupling. ${ }^{40}$ In one case, Apfel and coworkers were able to demonstrate that their $\mathrm{Ni}^{\mathrm{I}}$ complexes stabilized by the Triphos ligand 25 catalyzed the aryl-aryl Kumada cross-coupling at RT with low catalyst loadings $(0.5 \mathrm{~mol} \%)^{41}$ However, the complex did not afford any product with an alkyl Grignard, even at elevated temperatures. Another example of a $\mathrm{Ni}^{\mathrm{I}}$-catalyzed Kumada cross-coupling has been reported by the $\mathrm{Fu}$ group, ${ }^{42}$ in which the $\mathrm{Ni}^{\mathrm{I}} \mathrm{Br}(\mathrm{Ph}-\mathrm{BOX})$ complex catalyzed a $\mathrm{C} s p^{2}-\mathrm{C} s p^{3}$ cross-coupling reaction, the organohalide used was an activated $\alpha$-halocarbonyl substrate, and the reaction required longer reaction times (20 hr) and slightly higher catalyst loadings ( $7 \mathrm{~mol} \%)$. Overall, we consider that these unique results showing that isolated $\mathrm{Pd}^{\mathrm{I}}$ complexes are active catalysts for $\mathrm{Cs} p^{2}-$ 
$\mathrm{Csp} p^{3}$ cross-coupling reactions should have a significant impact toward the development of new catalytic applications for $\mathrm{Pd}^{\mathrm{I}}$ species in various organic transformations.

Table 2. A Kumada cross-coupling reaction catalyzed by Pd complexes.

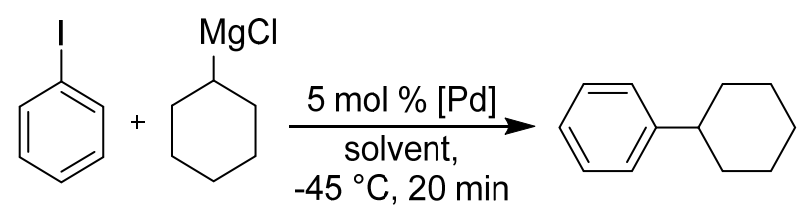

\begin{tabular}{cccc}
\hline Entry & {$[\mathrm{Pd}]$} & Solvent & Yield, $\%^{a}$ \\
\hline 1 & {$\left[\mathrm{Pd}^{0}\left(\mathrm{P}^{\mathrm{t}} \mathrm{Bu}_{3}\right)_{2}\right]$} & $\mathrm{DFB}$ & $11 \pm 1$ \\
2 & {$\left[\mathrm{Pd}^{\mathrm{I}}\left(\mathrm{P}^{\mathrm{B}} \mathrm{Bu}_{3}\right)_{2}\right]^{+}$} & $\mathrm{DFB}$ & $53 \pm 2$ \\
3 & $\mathbf{P d}-\mathbf{1}$ & $\mathrm{DFB}$ & $\mathbf{7 4} \pm \mathbf{3}^{b}$ \\
4 & $\mathbf{P d - 2}$ & $\mathrm{DFB}$ & $\mathbf{9 6} \pm \mathbf{3}^{b}$ \\
5 & $\mathbf{P d - 3}$ & $1: 9 \mathrm{MeCN}: \mathrm{DFB}^{c}$ & $8 \pm 1$ \\
6 & $\mathbf{P d - 4}$ & $1: 9 \mathrm{MeCN}: \mathrm{DFB}^{c}$ & $3 \pm 1$ \\
\hline
\end{tabular}

${ }^{a}$ Yields were determined using GC-MS with dodecane as the internal standard; no coupled products were observed in the absence of $[\mathrm{Pd}] .{ }^{b}$ The homocoupled product biphenyl was formed in less than $10 \%$ yield. ${ }^{c}$ Addition of $10 \quad$ MeCN was needed due to insolubility of the $\operatorname{Pd}(\mathrm{II})$ complexes in DFB.

Next, we sought to further probe the mechanism of the Csp ${ }^{2}$-Csp $p^{3}$ Kumada cross-coupling reaction catalyzed by Pd-1 and Pd-2. Based on the commonly accepted mechanism for crosscoupling reactions involving 2-electron oxidative addition (OA) and reductive elimination (RE) steps, we propose the mechanism depicted in Fig. 3A. The initial step involves the oxidative addition of $\mathrm{PhI}$ to the $\mathrm{Pd}^{\mathrm{I}}$ center to give the $\mathrm{Pd}^{\mathrm{III}}$ intermediate a, followed by transmetalation with the Grignard reagent to yield species $\mathbf{b}$, which then would undergo RE to yield the final C-C coupled product. To provide further experimental evidence for this mechanism, the reaction between Pd-2 and PhI was studied by EPR. Upon addition of 1 eq. PhI to a solution of Pd-2 at $45^{\circ} \mathrm{C}$, the rhombic EPR signal corresponding to Pd-2 disappears and a new pseudo-axial signal forms within minutes at $-45^{\circ} \mathrm{C}$ (fig. S13). This EPR signal is stable for minutes at RT and it can be simulated using the following parameters: $g_{\mathrm{x}}=2.003, g_{\mathrm{y}}=2.009, g_{\mathrm{z}}=2.065(A \mathrm{p}=100 \mathrm{G}$, Fig. 3B). The presence of ${ }^{31} \mathrm{P}$ superhyperfine coupling in the $\mathrm{z}$ direction indicates that the $\mathrm{P}^{\mathrm{t}} \mathrm{Bu}$ ligand is still bound to Pd center. Given the proposed oxidative addition step of PhI to Pd-2, we tentatively 
assign this new EPR signal to the $\mathrm{Pd}^{\mathrm{III}}$ species a (Fig. 3A). While additional experimental and computational studies are needed to unambiguously confirm the nature of this paramagnetic species, the significantly different resulting EPR signal compared to that of the initial $\mathrm{Pd}^{\mathrm{I}}$ complex Pd-2 supports a change in the oxidation state of the Pd center.
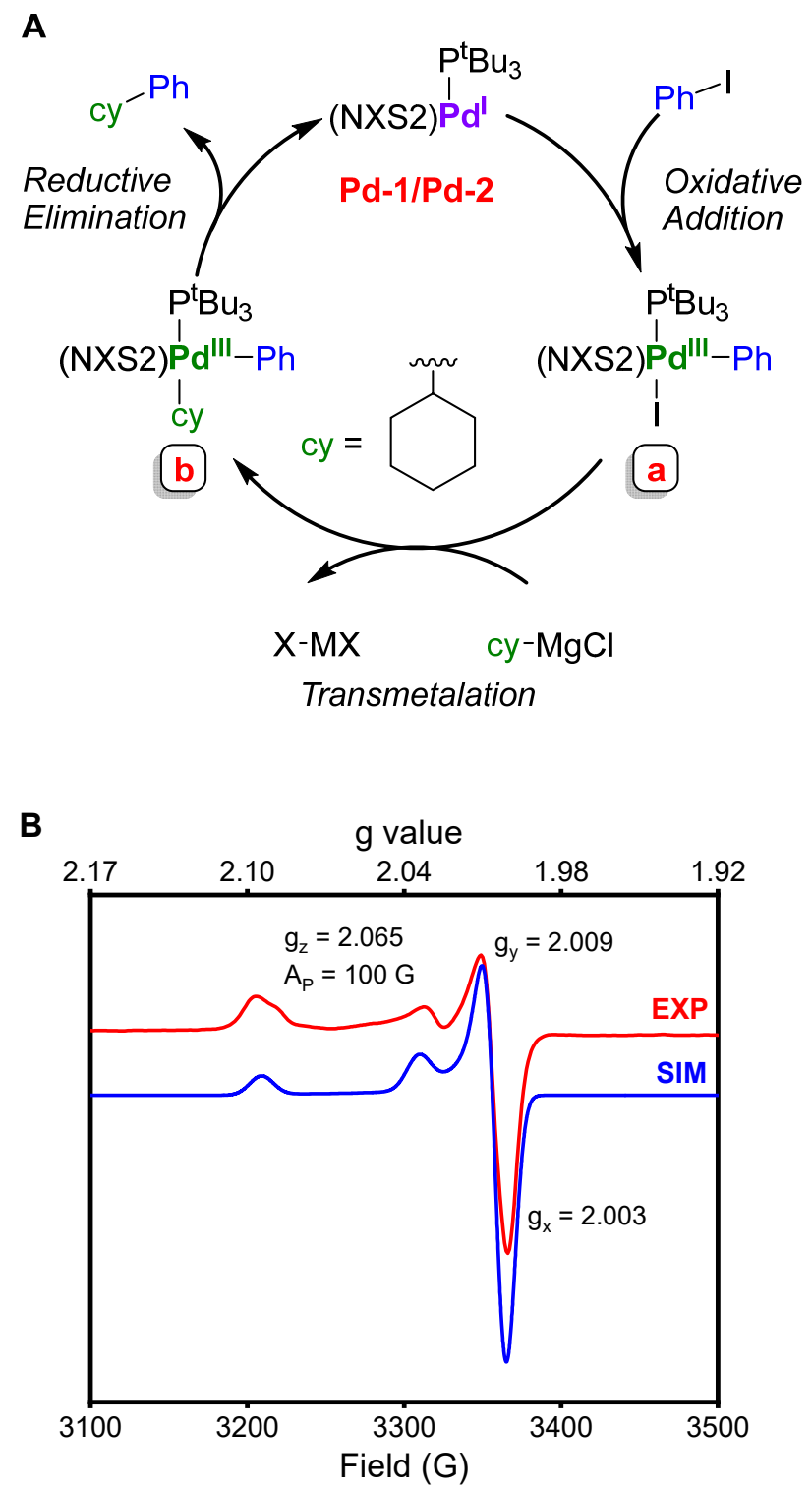

Fig. 3. (A) Proposed mechanism for the $\mathrm{Pd}^{\mathrm{I}}$-catalyzed Kumada cross-coupling between $\mathrm{PhI}$ and cyclohexylMgCl. (B) EPR spectrum (red line) of the resulting putative $\mathrm{Pd}^{\mathrm{III}}$ species a formed upon the reaction of Pd-2 with and 1 equiv $\mathrm{PhI}$ for $10 \mathrm{~min}$ at RT (spectrum collected in 1:1 DFB:2MeTHF glass, $77 \mathrm{~K}$ ) and the simulated EPR spectrum (blue line) using the following parameters: $g_{\mathrm{x}}=2.003, g_{\mathrm{y}}=2.009, g_{\mathrm{z}}=2.065\left(A_{P}=100 \mathrm{G}\right)$. 
A

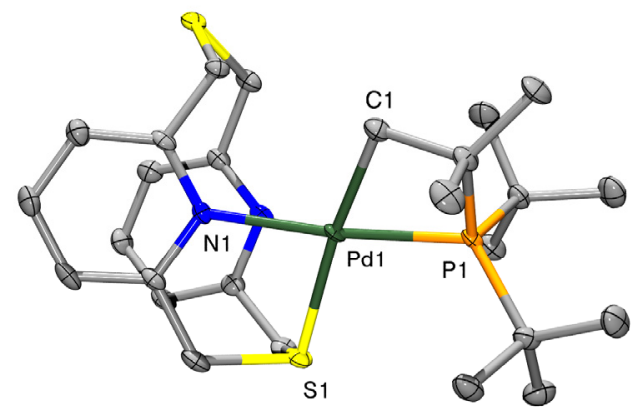

B

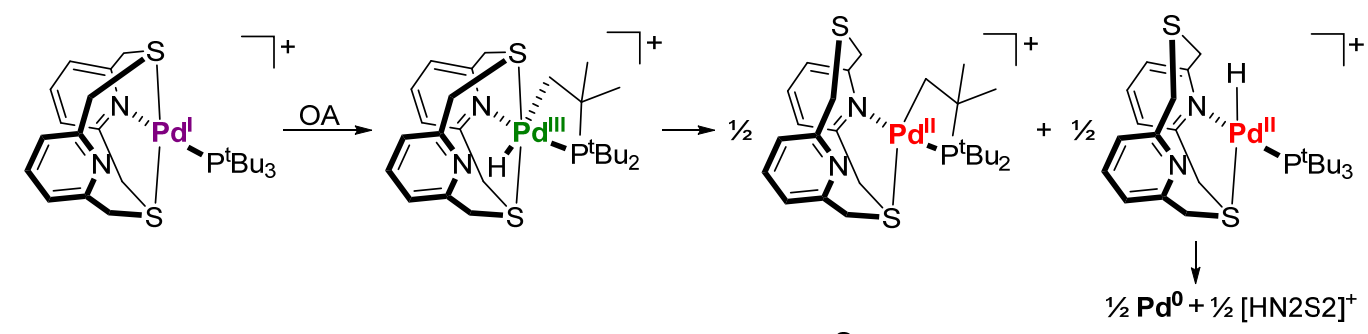

C

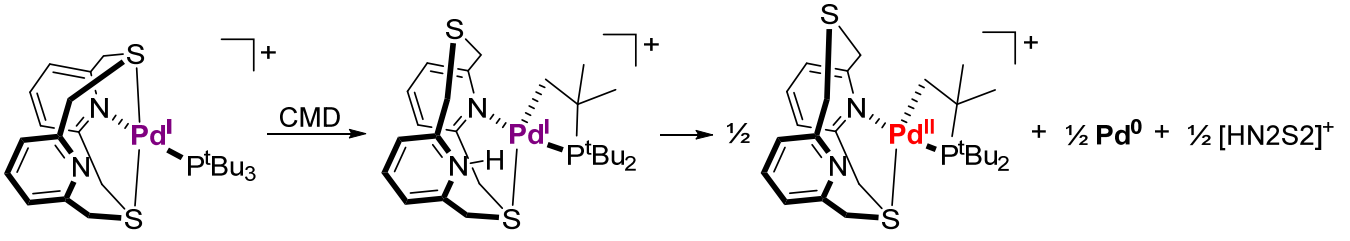

Fig. 4. ORTEP representation (50\% probability ellipsoids) of the cation of Pd-5. Selected bond distances $(\AA)$ angles $\left(^{\circ}\right)$ : Pd1-C1 2.093(3), Pd1-N1 2.166(2), Pd1-P1 2.2128(8), Pd1-S1 2.3617(8), C1-Pd1-S1 168.35(8), N1-Pd1-P1 172.12 (7).

Interestingly, upon storing the Pd-1 complex in $\mathrm{MeCN}$ at $-35{ }^{\circ} \mathrm{C}$, light yellow crystals were obtained upon layering with $\mathrm{Et}_{2} \mathrm{O}$. Single crystal X-ray structural analysis of this product reveals the formation of the cyclometalated complex $\left[(\mathrm{N} 2 \mathrm{~S} 2) \mathrm{Pd}^{\mathrm{II}}\left(\mathrm{P}^{\mathrm{t}} \mathrm{Bu}_{2} \mathrm{CMe}_{2} \mathrm{CH}_{2}\right)\right]^{+}, \mathbf{P d}-\mathbf{5}$, in which the $\mathrm{Pd}^{\mathrm{II}}$ species adopts a distorted square planar geometry with a geometry index $\tau_{4}=0.127$ (Fig. 4A). ${ }^{37}$ The $\mathrm{Pd}-\mathrm{P}$ and $\mathrm{Pd}-\mathrm{C}$ bond lengths and the $\mathrm{P} 1-\mathrm{Pd} 1-\mathrm{C} 1$ bite angle for the cyclometalated phosphine are comparable to the previously cyclometalated $\mathrm{Pd}^{\mathrm{II}}$ complex $\left[\left(\mathrm{P}^{t} \mathrm{Bu}_{3}\right) \mathrm{Pd}\left(\mathrm{CH}_{2} \mathrm{C}\left(\mathrm{CH}_{3}\right)_{2} \mathrm{P}^{t} \mathrm{Bu}_{2}\right)(\mathrm{OAc})\right] \mathrm{HOAc} .{ }^{43}$ Notably, there are only a few examples of other similar mononuclear cyclometalated $\mathrm{Pd}^{\mathrm{II}}$ complexes, ${ }^{43-45}$ and to the best of our knowledge formation of Pd-5 is the first example of an intramolecular $\mathrm{C}-\mathrm{H}$ bond activation that likely proceeds at $\mathrm{Pd}^{\mathrm{I}}$ center. In 2016, Chaplin et al. and Ozerov et al. have independently observed a similar cyclometallation process that was proposed to occur at the $\mathrm{Pt}^{\mathrm{I}}$ center of the $\left[\mathrm{Pt}^{\mathrm{I}}\left(\mathrm{P}^{\mathrm{t}} \mathrm{Bu}_{3}\right)_{2}\right]^{+}$ complex, yielding a mixture of $\mathrm{Pt}^{\mathrm{II}}$ cyclometalated and $\mathrm{Pt}^{\mathrm{II}}$-hydride complexes. ${ }^{35,36}$ However, while 
Chaplin et al. have proposed the analogous $\mathrm{C}-\mathrm{H}$ bond activation and cyclometallation to occur at the $\mathrm{Pd}^{\mathrm{I}}$ congener $\left[\mathrm{Pd}^{\mathrm{I}}\left(\mathrm{P}^{t} \mathrm{Bu}_{3}\right)_{2}\right]^{+}$, only indirect NMR evidence from an intractable reaction mixture was provided for such a cyclometalated $\mathrm{Pd}^{\mathrm{II}}$ complex. Therefore, our ability to obtain a solid state structure for the unique complex Pd-5 further underscores the utility of the employed NXS2 ligands in stabilizing novel $\mathrm{Pd}^{\mathrm{I}}$ species and allowing for the study of their reactivity. While detailed mechanistic studies are needed, the formation of the cyclometalated complex Pd-5 could be proposed to occur via one of the following mechanisms: 1) an oxidative addition (OA) pathway (Fig. 4B), or 2) a concerted metalation-deprotonation (CMD) pathway (Fig. 4C). For the first pathway, oxidative addition of the $\mathrm{C}-\mathrm{H}$ bond to the $\mathrm{Pd}^{\mathrm{I}}$ center would give an organometallic $\mathrm{Pd}^{\mathrm{III}}-$ $\mathrm{H}$ complex, which could subsequently comproportionate with another $\mathrm{Pd}^{\mathrm{I}}$ species to give a mixture of $\mathbf{P d}-\mathbf{5}$ and a Pd ${ }^{\mathrm{II}}-$ hydride species, the latter being expected to rapidly generate $\mathrm{Pd}^{0}$ and protonated N2S2 ligand. For the second pathway, a CMD step would occur first, which could be facilitated by the basic $\mathrm{N}$ atom of the uncoordinated pyridyl group of the N2S2 ligand, followed by disproportionation to yield the cyclometalated Pd-5 along with $\mathrm{Pd}^{0}$ and the protonated N2S2 ligand. Both mechanisms will lead to formation of 0.5 equiv of metallic $\mathrm{Pd}^{0}$, which was confirmed by the formation of a small amount of black precipitate in the reaction solution. By comparison, the formation of an analogous cyclometalated Pd complex was not observed for the NCHS2 analog Pd-2 - which is also more thermally stable, presumably due to the absence of a second pyridyl group in NCHS2 would eliminate an accessible basic site needed for a potential CMD process.

In summary, we have synthesized and characterized two novel mononuclear $\mathrm{Pd}^{\mathrm{I}}$ complexes stabilized by the dithiapyridinophane ligands N2S2 and NCHS2. Both complexes were fully characterized through X-ray diffraction, Evans method, UV-Vis and EPR spectroscopies, and DFT calculations to confirm the formal +1 oxidation state assignment for the Pd center. Furthermore, Pd-1 and Pd-2 are active catalysts for the Kumada Csp ${ }^{2}-C s p^{3}$ cross-coupling reaction, while Pd1 also exhibited what seems to be an unprecedented $\mathrm{C}-\mathrm{H}$ bond activation at a $\mathrm{Pd}^{\mathrm{I}}$ center. These findings underline the importance of understanding the reactivity of low-valent Pd intermediates and propose a fresh perspective for $\mathrm{Pd}^{\mathrm{I}} / \mathrm{Pd}^{\mathrm{III}}$ catalytic cycles present in a range of Pd-catalyzed organic transformations. 


\section{References and Notes}

1. Hartwig, J. F. Organotransition Metal Chemistry: From Bonding to Catalysis. (University Science Books, 2010).

2. Wu, X. F., Anbarasan, P., Neumann, H. \& Beller, M. From Noble Metal to Nobel Prize: Palladium-Catalyzed Coupling Reactions as Key Methods in Organic Synthesis. Angew. Chem., Int. Ed. 49, 9047-9050 (2010).

3. Johansson Seechurn, C. C., Kitching, M. O., Colacot, T. J. \& Snieckus, V. Palladiumcatalyzed cross-coupling: a historical contextual perspective to the 2010 Nobel Prize. Angew Chem Int Ed Engl 51, 5062-5085 (2012).

4. Gildner, P. G. \& Colacot, T. J. Reactions of the 21st Century: Two Decades of Innovative Catalyst Design for Palladium-Catalyzed Cross-Couplings. Organometallics 34, 5497-5508 (2015).

5. Negishi, E. Handbook of Organopalladium Chemistry for Organic Synthesis. (John Wiley \& Sons, 2002).

6. Vilar, R., Mingos, D. M. P. \& Cardin, C. J. Synthesis and structural characterization of [Pd2( $\mu$-Br)2(PBut3)2], an example of a palladium(I)-palladium(I) dimer. Dalton Trans., 4313-4314 (1996).

7. Manolikakes, G. \& Knochel, P. Radical catalysis of Kumada cross-coupling reactions using functionalized Grignard reagents. Angew. Chem., Int. Ed. 48, 205-209 (2009).

8. Hruszkewycz, D. P., Wu, J., Hazari, N. \& Incarvito, C. D. Palladium(I)-bridging allyl dimers for the catalytic functionalization of $\mathrm{CO}_{2}$. J. Am. Chem. Soc. 133, 3280-3283 (2011).

9. Aufiero, M., Proutiere, F. \& Schoenebeck, F. Redox Reactions in Palladium Catalysis: On the Accelerating and/or Inhibiting Effects of Copper and Silver Salt Additives in Cross-Coupling Chemistry Involving Electron-rich Phosphine Ligands. Angew. Chem., Int. Ed., 10.1002/anie.201202504 (2012).

10. Bonney, K. J., Proutiere, F. \& Schoenebeck, F. Dinuclear Pd(I) complexes-solely precatalysts? Demonstration of direct reactivity of a $\operatorname{Pd}(\mathrm{I})$ dimer with an aryl iodide. Chem. Sci. 4, 4434-4439 (2013).

11. Kalvet, I., Bonney, K. J. \& Schoenebeck, F. Kinetic and Computational Studies on Pd(I) Dimer-Mediated Halogen Exchange of Aryl Iodides. Journal of Organic Chemistry 79, 12041-12046 (2014).

12. Liu, Q. et al. Recent Advances on Palladium Radical Involved Reactions. ACS Catal. 5, 61116137 (2015).

13. Yin, G. Y., Kalvet, I. \& Schoenebeck, F. Trifluoromethylthiolation of Aryl Iodides and Bromides Enabled by a Bench-Stable and Easy-To-Recover Dinuclear Palladium(I) Catalyst. Angew. Chem., Int. Ed. 54, 6809-6813 (2015).

14. Chen, X. Y., Pu, M. P., Cheng, H. G., Sperger, T. \& Schoenebeck, F. Arylation of Axially Chiral Phosphorothioate Salts by Dinuclear Pd-I Catalysis. Angew. Chem., Int. Ed. 58, 1139511399 (2019).

15. Liu, Q. et al. Recent Advances on Palladium Radical Involved Reactions. ACS Catal. 5, 61116137 (2015). 
16. Cui, P. \& Iluc, V. M. Redox-induced umpolung of transition metal carbenes. Chem. Sci. 6, 7343-7354 (2015).

17. Parasram, M., Chuentragool, P., Sarkar, D. \& Gevorgyan, V. Photoinduced Formation of Hybrid Aryl Pd-Radical Species Capable of 1,5-HAT: Selective Catalytic Oxidation of Silyl Ethers into Silyl Enol Ethers. J. Am. Chem. Soc. 138, 6340-6343 (2016).

18. Jaworski, J. N., McCann, S. D., Guzei, I. A. \& Stahl, S. S. Detection of Palladium(I) in Aerobic Oxidation Catalysis. Angew. Chem., Int. Ed. 56, 3605-3610 (2017).

19. Simpson, Q., Sinclair, M. J. G., Lupton, D. W., Chaplin, A. B. \& Hooper, J. F. Oxidative Cross-Coupling of Boron and Antimony Nucleophiles via Palladium(I). Org. Lett. 20, 55375540 (2018).

20. Torres, G. M., Liu, Y. \& Arndtsen, B. A. A dual light-driven palladium catalyst: Breaking the barriers in carbonylation reactions. Science 368, 318 (2020).

21. Zhao, B. et al. Palladium-Catalyzed Dual Ligand-Enabled Alkylation of Silyl Enol Ether and Enamide under Irradiation: Scope, Mechanism, and Theoretical Elucidation of Hybrid Alkyl Pd(I)-Radical Species. ACS Catal. 10, 1334-1343 (2020).

22. Shaughnessy, K. H. Development of Palladium Precatalysts that Efficiently Generate $\operatorname{LPd}(0)$ Active Species. Israel Journal of Chemistry 60, 180-194 (2020).

23. Fujiwara, S. \& Nakamura, M. Electron Spin Resonance of Pd(I) .2. Gamma-Irradiated Single Crystals of K2pdc14 and (Nh4)2pdc14. J. Chem. Phys. 54, 3378-3380 (1971).

24. Nakamura, M. \& Fujiwara, S. ELECTRON SPIN RESONANCE OR Pd(I). III: The Nature of the Metal-ligand Bonds in Square Planar Complexes of Palladium(I). J. Coord. Chem. 1, 221-227 (1972).

25. Broadley, K., Lane, G. A., Connelly, N. G. \& Geiger, W. E. Electrochemical routes to paramagnetic dinuclear and mononuclear palladium $\pi$ complexes stabilized by the pentaphenylcyclopentadienyl ligand. J. Am. Chem. Soc. 105, 2486-2487 (1983).

26. Lane, G. A., Geiger, W. E. \& Connelly, N. G. Palladium(I) .pi.-radicals. Electrochemical preparation and study of their reaction pathways. J. Am. Chem. Soc. 109, 402-407 (1987).

27. Blake, A. J., Gould, R. O., Hyde, T. I. \& Schröder, M. Stabilization of monovalent palladium by tetraaza macrocyles. J. Chem. Soc., Chem. Commun., 431-433 (1987).

28. Blake, A. J., Gould, R. O., Hyde, T. I. \& Schröder, M. Tetrahedral Distortion in Palladium(ii) Macrocyclic Complexes: The Single Crystal X-Ray Structure of $[\mathrm{Pd}(\mathrm{tbc})](\mathrm{PF} 6) 2=0.4 \mathrm{MeN} 02$ $($ tbc $=1,4,8,1$ 1-tetrabenzyl-1,4,8,11 -tetra-azacyclotetradecane. J. Chem. Soc., Chem. Commun., 1731-1733 (1987).

29. Reid, G., Blake, A. J., Hyde, T. I. \& Schröder, M. Stereochemical and redox properties of palladium complexes of 1,4,10,13-tetrathia-7,16-diazacyclooctadecane. J. Chem. Soc., Chem. Commun., 1397-1399 (1988).

30. Luo, J., Tran, G. N., Rath, N. P. \& Mirica, L. M. Detection and Characterization of Mononuclear Pd(I) Complexes Supported by N2S2 and N4 Tetradentate Ligands. Inorg. Chem. 59, 15659-15669 (2020). 
31. Fafard, C. M., Adhikari, D., Foxman, B. M., Mindiola, D. J. \& Ozerov, O. V. Addition of Ammonia, Water, and Dihydrogen Across a Single Pd-Pd Bond. J. Am. Chem. Soc. 129, 10318-10319 (2007).

32. Huacuja, R. et al. Reactivity of a $\operatorname{Pd}(\mathrm{I})-\mathrm{Pd}(\mathrm{I})$ Dimer with O2: Monohapto Pd Superoxide and Dipalladium Peroxide in Equilibrium. J. Am. Chem. Soc. 133, 3820-3823 (2011).

33. Hazari, N. \& Hruszkewycz, D. P. Dinuclear Pd(I) complexes with bridging allyl and related ligands. Chem. Soc. Rev. 45, 2871-2899 (2016).

34. Fricke, C., Sperger, T., Mendel, M. \& Schoenebeck, F. Catalysis with Palladium(I) Dimers. Angew Chem Int Ed Engl (2020).

35. Troadec, T. et al. One-Electron Oxidation of $[\mathrm{M}((\mathrm{PBu} 3)-\mathrm{Bu}-\mathrm{t})(2)](\mathrm{M}=\mathrm{Pd}, \mathrm{Pt})$ : Isolation of Monomeric $[\mathrm{Pd}((\mathrm{PBu} 3)-\mathrm{Bu}-\mathrm{t})(2)](+)$ and Redox-Promoted C-H Bond Cyclometalation. Angew. Chem., Int. Ed. 55, 3754-3757 (2016).

36. MacInnis, M. C. et al. Cationic Two-Coordinate Complexes of Pd(I) and Pt(I) Have Longer Metal-Ligand Bonds Than Their Neutral Counterparts. Chem 1, 902-920 (2016).

37. Okuniewski, A., Rosiak, D., Chojnacki, J. \& Becker, B. Coordination polymers and molecular structures among complexes of mercury(II) halides with selected 1-benzoylthioureas. Polyhedron 90, 47-57 (2015).

38. Morton, J. R. \& Preston, K. F. Atomic parameters for paramagnetic resonance data. Journal of Magnetic Resonance (1969) 30, 577-582 (1978).

39. Lin, C. Y. \& Power, P. P. Complexes of Ni(i): a "rare" oxidation state of growing importance. Chem. Soc. Rev. 46, 5347-5399 (2017).

40. Miyazaki, S., Koga, Y., Matsumoto, T. \& Matsubara, K. A new aspect of nickel-catalyzed Grignard cross-coupling reactions: selective synthesis, structure, and catalytic behavior of a T-shape three-coordinate nickel(I) chloride bearing a bulky NHC ligand. Chem Commun (Camb) 46, 1932-1934 (2010).

41. Iffland, L., Petuker, A., Van Gastel, M. \& Apfel, U.-P. Mechanistic Implications for the Ni(I)Catalyzed Kumada Cross-Coupling Reaction. Inorganics 5 (2017).

42. Yin, H. \& Fu, G. C. Mechanistic Investigation of Enantioconvergent Kumada Reactions of Racemic alpha-Bromoketones Catalyzed by a Nickel/Bis(oxazoline) Complex. J. Am. Chem. Soc. 141, 15433-15440 (2019).

43. Henderson, W. H., Alvarez, J. M., Eichman, C. C. \& Stambuli, J. P. Characterization, Reactivity, and Potential Catalytic Intermediacy of a Cyclometalated Tri-tert-butylphosphine Palladium Acetate Complex. Organometallics 30, 5038-5044 (2011).

44. Barrios-Landeros, F., Carrow, B. P. \& Hartwig, J. F. Autocatalytic oxidative addition of $\mathrm{PhBr}$ to $\mathrm{Pd}(\mathrm{PtBu} 3) 2$ via $\mathrm{Pd}(\mathrm{PtBu} 3) 2(\mathrm{H})(\mathrm{Br})$. J. Am. Chem. Soc. 130, $5842-5843$ (2008).

45. Tan, Y., Barrios-Landeros, F. \& Hartwig, J. F. Mechanistic studies on direct arylation of pyridine $\mathrm{N}$-oxide: evidence for cooperative catalysis between two distinct palladium centers. J. Am. Chem. Soc. 134, 3683-3686 (2012). 
Acknowledgments: We thank Dr. Yung-Ching Wang for his help with recording the initial EPR spectra for these studies. We also thank all the research facilities in the Department of Chemistry at the University of Illinois at Urbana-Champaign for their help.

Funding: This project was initially funded by the following funding source(s):

\section{Author contributions:}

Conceptualization: L.M.M., G.N.T.

Methodology: G.N.T, L.M.M

Investigation: G.N.T., B.S.B.

Visualization: G.N.T, B.S.B, L.M.M

Funding acquisition: L.M.M

Project administration: L.M.M

Supervision: L.M.M

Writing - original draft: G.N.T

Competing interests: The authors declare no competing financial interests.

Data and materials availability: CCDC numbers 2079193-2079197 contain the supplementary crystallographic data for this paper. These data can be obtained free of charge via www.ccdc.cam.ac.uk/data_request/cif, or by emailing data_request@eccdc.cam.ac.uk, or by contacting The Cambridge Crystallographic Data Centre, 12 Union Road, Cambridge CB2 1EZ, UK; fax: +44 1223 336033. All other experimental, spectroscopic characterization, and X-ray crystallographic data are included in the supplementary materials.

\section{Supplementary Materials}

Materials and Methods

25 Supplementary Text

Figs. S1 to S24

Tables S1 to S12 


\section{References (\#\#\#\#)}

Data S1 to S2 